\title{
Narrative review of metabolomics in cardiovascular disease
}

\author{
Julian Müller ${ }^{1}$, Thomas Bertsch ${ }^{2}$, Justus Volke ${ }^{1}$, Alexander Schmid ${ }^{1}$, Rebecca Klingbeil ${ }^{1}$, \\ Yulian Metodiev ${ }^{1}$, Bican Karaca ${ }^{1}$, Seung-Hyun Kim ${ }^{1}$, Simon Lindner ${ }^{1}$, Tobias Schupp ${ }^{1}$, Maximilian Kittel ${ }^{3}$, \\ Gernot Poschet ${ }^{4}$, Ibrahim Akin ${ }^{1}$, Michael Behnes ${ }^{1}$
}

${ }^{1}$ First Department of Medicine, Faculty of Medicine Mannheim, University of Heidelberg, Mannheim, Germany; ${ }^{2}$ Institute of Clinical Chemistry, Laboratory Medicine and Transfusion Medicine, Nuremburg General Hospital, Paracelsus Medical University, Nuremberg, Germany; ${ }^{3}$ Institute for Clinical Chemistry, Faculty of Medicine Mannheim, Heidelberg University, Mannheim, Germany; ${ }^{4}$ Centre for Organismal Studies (COS), University of Heidelberg, Heidelberg, Germany

Contributions: (I) Conception and design: J Müller, M Behnes, A Akin; (II) Administrative support: T Bertsch, SH Kim, S Lindner, T Schupp, M Kittel, G Poschet; (III) Provision of study materials or patients: J Volke, A Schmid, R Karaca, Y Metodiev, B Klingbeil; (IV) Collection and assembly of data: J Volke, A Schmid, R Karaca, Y Metodiev, B Klingbeil; (V) Data analysis and interpretation: J Müller, M Behnes, B Klingbeil, G Poschet; (VI) Manuscript writing: All authors; (VII) Final approval of manuscript: All authors.

Correspondence to: Prof Dr. med. Michael Behnes. First Department of Medicine, Faculty of Medicine Mannheim, University of Heidelberg, Theodor-Kutzer-Ufer 1-3, 68167 Mannheim, Germany. Email: michael.behnes@umm.de.

\begin{abstract}
Cardiovascular diseases are accompanied by disorders in the cardiac metabolism. Furthermore, comorbidities often associated with cardiovascular disease can alter systemic and myocardial metabolism contributing to worsening of cardiac performance and health status. Biomarkers such as natriuretic peptides or troponins already support diagnosis, prognosis and treatment of patients with cardiovascular diseases and are represented in international guidelines. However, as cardiovascular diseases affect various pathophysiological pathways, a single biomarker approach cannot be regarded as ideal to reveal optimal clinical application. Emerging metabolomics technology allows the measurement of hundreds of metabolites in biological fluids or biopsies and thus to characterize each patient by its own metabolic fingerprint, improving our understanding of complex diseases, significantly altering the management of cardiovascular diseases and possibly personalizing medicine. This review outlines current knowledge, perspectives as well as limitations of metabolomics for diagnosis, prognosis and treatment of cardiovascular diseases such as heart failure, atherosclerosis, ischemic and non-ischemic cardiomyopathy. Furthermore, an ongoing research project tackling current inconsistencies as well as clinical applications of metabolomics will be discussed. Taken together, the application of metabolomics will enable us to gain more insights into pathophysiological interactions of metabolites and disease states as well as improving therapies of patients with cardiovascular diseases in the future.
\end{abstract}

Keywords: Metabolomics; ischemic heart disease; atherosclerosis; heart failure

Submitted Jan 04, 2021. Accepted for publication Feb 24, 2021.

doi: $10.21037 /$ jtd-21-22

View this article at: http://dx.doi.org/10.21037/jtd-21-22

\section{Introduction}

It is not unpredictable that disorders in the cardiac energy metabolism are major contributors to many cardiovascular disease as the heart is the most metabolically demanding organ in the body (1). Furthermore, conditions often associated with cardiovascular disease pathogenesis can change cardiac function and myocardial metabolism. Alterations in substrate metabolism resulting from onset of cardiovascular disease can contribute to characteristic changes in the patient's metabolic profile $(2,3)$.

Thanks to new "omics" tools (genomics, transcriptomics, proteomics and metabolomics) we now have a much broader understanding of pathophysiological molecular, cellular 


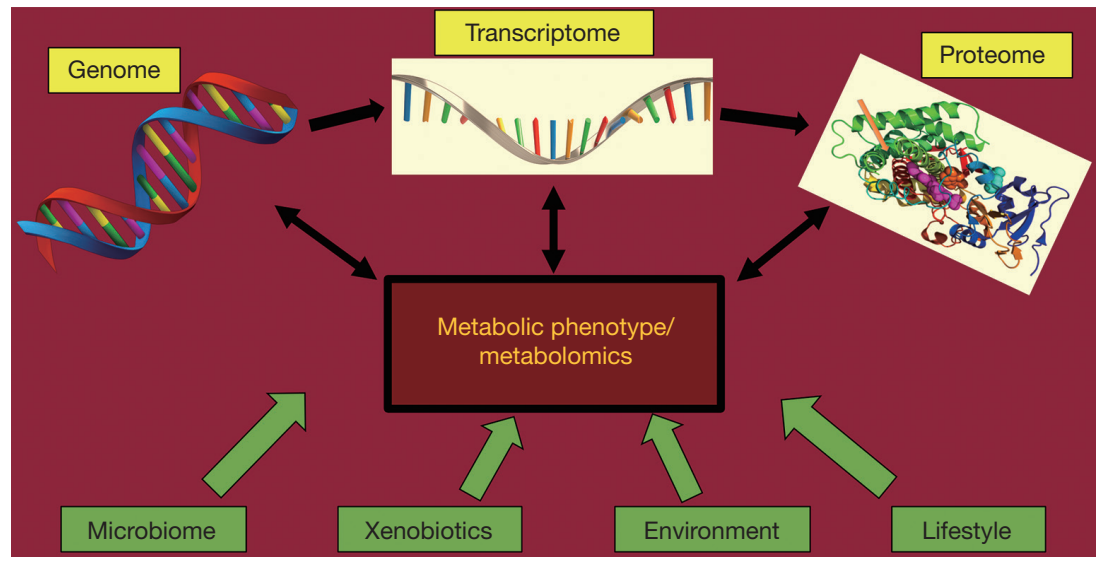

Figure 1 A metabolomics-centric view of the metabolic pathways. Genetic variations lead to changes in gene expression (transcriptome) which affect protein variations (proteome). The metabolic phenotype is influenced by many factors. In turn, variations in metabolism can modify genomic, transcriptomic and proteomic outputs.

and functional alterations that take place in cardiovascular diseases (4). Modern metabolomics technologies represent a tool to measure a plethora of metabolites in biological samples including blood plasma, urine and tissues. These snapshots might serve as prognostic and diagnostic tools to identify early specific changes during onset and progression of cardiovascular disease (5) (Figure 1). Therefore, metabolomics are representing an important tool to provide further insights into the pathophysiology of cardiovascular diseases and advance clinicians' understanding of pathogenesis of cardiovascular disease.

We present the following article in accordance with the Narrative Review reporting checklist (available at http:// dx.doi.org/10.21037/jtd-21-22).

\section{Metabolomic analytic techniques}

Currently, two techniques dominate metabolomic studies: nuclear magnetic resonance (NMR) and mass spectrometry (MS) (6). Both techniques are able to identify and quantify different metabolites in an automated manner. Due to the complexity of the human metabolome, none of the available techniques is able to provide an overview of the complete metabolome in biological samples due to the chemical diversity as well as very broad concentration range of different metabolites and metabolite classes (7-9). Therefore, often more than one analytical technique is applied. NMR delivers detailed information about the structure allowing identification of the molecules. MS-based platforms coupled to liquid or gas chromatography (GC) separation systems yield better sensitivity, but molecules must be ionized to be detected via MS and the selected separation methods play a huge role which molecules can be analyzed $(7,10,11)$. Detailed reviews with focus on technical features of metabolomic platforms have previously been published (12).

\section{Nuclear magnetic resonance}

NMR was the first analytical platform and is highly selective for the respective metabolite and non-destructive with minimal sample preparation $(11,13-15)$. The basis of this technique is to identify the metabolites by chemical shifts in resonance frequency. Advantages of NMR are robust, reproducible results with minimal sample preparation at low costs (16). Multiple spectral libraries provide detailed information about the metabolite structure for identification, especially using multidimensional NMR including $1 \mathrm{D}$, fast 2D or ultrafast schemes (17-19). Furthermore, no chemical derivatization is needed for NMR analysis reducing sample preparation, duration and analytic variability $(15,20)$.

Proton NMR (H-NMR), as most popular NMR techniques, displays fast acquisition times with high sensitivity of protons to NMR and abundance of protons in organic molecules (21). H-nuclei exhibit a small range in chemical shift. Therefore, NMR can be used as 2-dimensional NMR to detect and avoid co-resonances of metabolites with similar chemical shifts (22).

In contrast, C-atoms have a wider chemical shift, thus 
C-NMR delives detailed positional information about stable isotope compounds (23).

However, the sensitivity of NMR assays is poorer compared to MS which relates to the strength of the magnet (5). Via NMR, quantification of only around 100 of the most abundant metabolites is possible while low abundant compounds cannot be determined in complex sample matrices $(24,25)$. Furthermore, much larger amounts of starting material are needed for analyses via NMR, in comparison to MS. This is especially crucial in studies using mice, where only small amounts of tissue or biofluids are available or for studies with human tissue material of low availability. In the last years, most metabolomic studies used NMR as a stand-alone technique, however a complimentary approach with MS is becoming increasingly popular, as it improves sensitivity and metabolome coverage (26-28).

\section{Mass spectrometry}

MS identifies metabolites on basis of their mass/ charge ratio. Mass spectrometers consist of three basic components: The ionization source, the mass analyser and the ion detector (29). Prior to infusion into the MS source, often separation of metabolites within processed biological samples is applied using liquid chromatography (LC) or GC (30). This chromatographical separation increases selectivity and confidence in compound identification while it decreases potential ion suppression effects in the mass spectrometer due to fewer co-eluting compounds reaching the mass detector at a given time (30).

GC based MS requires volatile metabolites and gasphase chemistry. However, because most metabolites are not naturally volatile, they must be derivatized artificially, which requires a variety of preparations (31). Thus, unstable and easily degradable metabolites such as $\alpha$-keto acids, acylCoAs and acylcarnitines are not optimally suitable for GCMS. Until now, for most GC-based targeted metabolomic studies, quadrupole GC-MS is used (32). Its main function is to select ions for more accurate analyses, since mass selectivity and mass range is limited by various parameters. Using a time of flight (TOF) analyser, mass accuracy and range can be improved (33). A TOF MS analyser is able to identify a mass/charge ratio value based on the time taken by a pulse of ions to traverse a known distance (34). Because even well-prepared samples might exhibit identification problems with large molecules due to similar mass/charge ratio, GC-MS is often combined with tandem MS (MS/ MS) (35-37). Via tandem MS, greater certainty in the identification of large ions is provided due to specific fragment ions and fragment patterns (34). Combination of GC-Q-TOF and tandem MS systems offers high separation capability and good mass accuracy, which is ideal for nontargeted metabolomic profiling (38). However, limited metabolite coverage and restricted usability for labile compounds are still a problem, even for the latest systems.

LC is a separation technique often used for involatile and polar compounds with high molecular weight. However, also smaller metabolites can be separated using LC. LC is able to separate a wide range of metabolites, optimal for high-throughput and extensive metabolomic analyses (39). After injection into a moving stream of the mobile phase (solvent mixture), samples are transferred onto the chromatographic column containing a stationary phase of diverse chemical composition. Separation is based on the compound's affinity to mobile phase versus stationary phase (40). Therefore, different types of chromatographic columns can be used providing very diverse separation properties (41). In normal-phase chromatography, mobile phase is nonpolar and stationary phase is polar, and molecules separate according to their polarity. Reversedphase chromatography operates vice versa and is more efficient, stable and withholds polar analytes, therefore best applied for nonpolar metabolites such as glycerolipids, phospholipids, fatty acids, acyl-carnitines and acyl-CoAs. In hydrophilic interaction chromatography the stationary phase is polar, similar to normal-phase chromatography. However, the solvent phase is highly hydrophobic enhancing the retention and separation of extremely polar analytes. Hydrophilic interaction chromatography is therefore used for nucleotides, phosphate compounds, organic acids and sugar monomers $(42,43)$.

\section{Heart failure}

The healthy human heart is able to select its substrates for energy production depending on the substrate availability and the myocardial energy demand $(44,45)$. Oxidative phosphorylation, oxygen consumption and ATP production is reduced during heart failure (HF) resulting in lower ATP levels compared to healthy hearts (46). Metabolism of one substrate can inhibit utilization of an alternative one. An example was previously published for the glucose-fatty acid cycle, where a higher release of fatty acids (FA) and ketone bodies lead to abnormalities in the carbohydrate metabolism (47). The failing heart gradually loses its ability to select substrates flexibly. In early stages of HF, glucose 


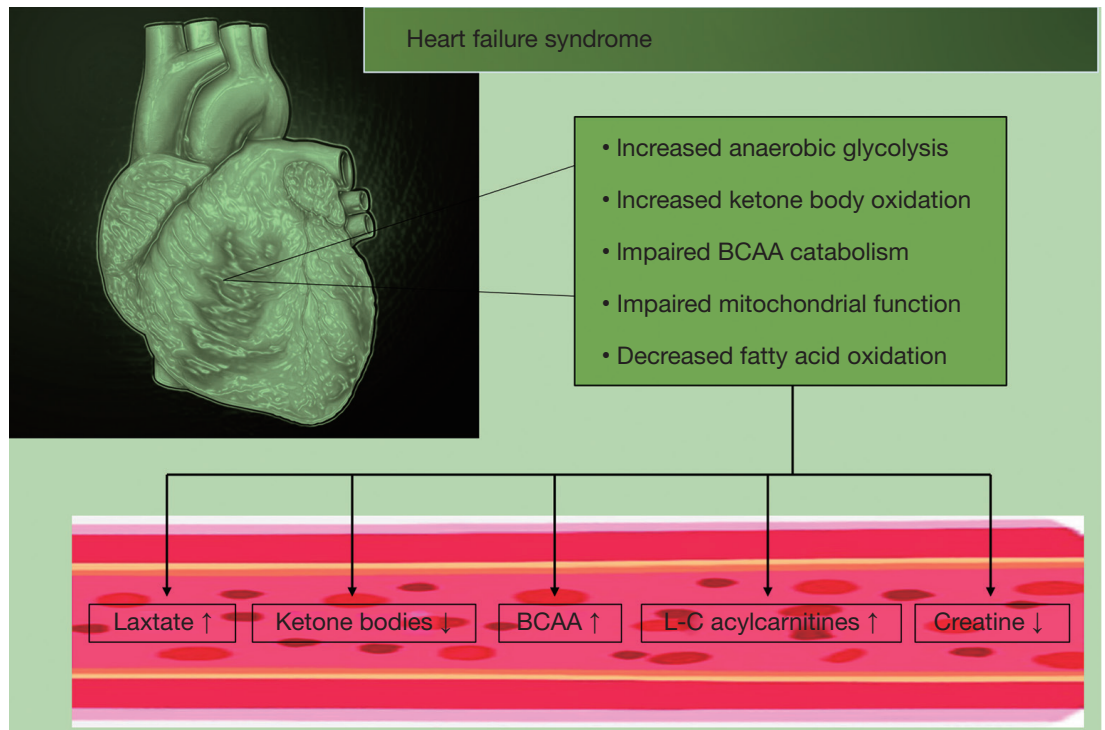

Figure 2 Heart failure is characterized by low energy state with a drop in CK activity and its substrate creatine. During heart failure the oxidative energy metabolism and the mitochondrial function is reduced, which is compensated by increased anaerobic glycolysis. Peripheral metabolomic profiles show often increased lactate, BCAA and L-C acylcarnitine levels. Furthermore, the failing heart's reliance on ketone bodies is increased to compensate the reduced fatty acid oxidation in the mitochondrion. BCAA, branch-chained amino acids; CK, creatine kinase; L-C, long-chain.

and FA metabolism is enhanced. As HF progresses, chronic hemodynamic stress leads to an increased carbohydrate metabolization instead of FA (48). End-stage HF is characterized by reduction in both substrates (49) (Figure 2).

\section{Low energy state}

The concept of the failing heart as an engine out of fuel is in the meantime decades old (50-52). A major reason for attention of this topic is that energy-saving treatment options for heart failure such as ACE inhibitors, angiotensin II inhibitors and beta-blockers improve prognosis of patients with heart failure (53-58). Lack of cardiac energy has a major role in heart failure (59). The human heart generates impressive amounts of ATP daily to maintain the needs of its contractile elements and ion pumps. The creatine kinase (CK) system provides an important mechanism to buffer and maintain cellular ATP levels by rapidly transferring high-energy phosphates from phosphocreatine (PCr) to adenosine diphosphate (ADP) $(60,61)$. This reaction generates ATP 10 times faster than oxidative phosphorylation (62). During HF, studies have shown a drop in CK activity of around $20-45 \%$ (3). This is followed by a significant decrease in the PCr/ATP ratio, known as an important parameter of cardiac metabolism. This ratio correlates with New York Heart Association (NYHA) classes, systolic and diastolic function (63-65).

Together with CK, its substrate, creatine, is reduced by $50 \%$ in the failing heart (3). This is probably secondary to downregulation of the creatine transporter (responsible for myocardial uptake of this metabolite from the circulation) (Figure 2) (66). Nevertheless, transgenic overexpression of the creatine transporter leads to a decrease in ATP levels in myocardium of rats and reduced left ventricular function despite significant increasing myocardial creatine concentrations and $\mathrm{PCr} / \mathrm{ATP}$ ratio (67). This finding emphasizes the difficulty to transfer a metabolomic finding to the pathophysiology of HF.

Energy starvation during HF results in essential ion transport abnormalities including $\mathrm{Ca}^{2+}$ release and uptake (68-71). $\mathrm{Ca}^{2+}$ is known to be crucial for the cardiac muscle contraction $(72,73)$. Furthermore, it is essential for regulation of key Krebs cycle enzymes affecting mitochondrial metabolism all resulting in a diminished ATP production (74,75). Despite efforts and progress in this research field of cardiac energy metabolism during $\mathrm{HF}$, there is still no simple answer to the question whether changes in the substrate utilization are cause or result of the 
disease.

\section{Fatty acid metabolism}

To date, several abnormalities in the process of FA metabolism have been identified among HF patients. Free FA can cross the lipid bilayer (76). After entering the cytoplasm, free FA are either bound by heart-type cytoplasmatic fatty acid-binding protein $\left(\mathrm{H}-\mathrm{FABP}_{\mathrm{c}}\right)$ or are converted into acyl-CoA which can be transported into mitochondria, where acyl-CoA is oxidized generating ATP (76).

Attention has primarily focused on changes in acylcarnitine profiles, since acylcarnitines are derivatives of fatty acyl-CoAs, reflecting changes in FA oxidation rates and specific defects in the mitochondrial $\beta$-oxidation machinery (77).

Elevated levels of circulating C16 and C18:1 acylcarnitines in patients with end-stage heart failure were associated with an increased risk for mortality and rehospitalization due to HF (78). Consequently, after implantation of left ventricular assist device (LVAD) circulating long-chained (L-C) acylcarnitines decreased (78). In line with these findings, among patients with heart failure with preserved ejection fraction (HFpEF) circulating L-C acylcarnitines were increased. Even higher levels are found among patients with heart failure with reduced ejection fraction (HFrEF) (79). Bedi et al. found controversial results, in which acylcarnitines were reduced in myocardial tissue from end-stage HF patients at the time of heart transplantation or implantation of LVAD compared to tissue from patients with no history of HF (80). The authors recruited only non-diabetic HF patients, whereas the previously mentioned study included a large fraction of HF patients with diabetes. In obese and diabetic patients circulating acylcarnitines are often elevated, possibly explaining this discrepancy between the above-mentioned studies (Figure 2) (81).

Decreased myocardial acylcarnitines might represent the impaired mitochondrial function and subsequent FA oxidation (82-84), which is in line with previous findings showing a reduction of $\mathrm{FA}$ oxidation during more severe stages of HF $(12,82,85,86)$. Results from studies in mice confirm these findings since both FA oxidation and protein expression are only mildly decreased in compensated HF, but markedly decreased in decompensated HF (82,87-89). So, it is plausible that many of these discrepancies in the acylcarnitine metabolism can be explained by the severity of HF, presence of underlying diabetes or obesity and the overall decline in left ventricular function (90). Future metabolomics studies need to consider these aspects and make distinct comparisons between these subgroups of HF patients.

\section{Glucose metabolism}

Glucose transport into myocytes is regulated by specific transmembrane glucose transporters (GLUTs) localized in the sarcolemma (91). Expression levels of GLUT-1 and GLUT-4 correlate positively with glucose uptake (92). Progression of HF is characterized by enhanced utilization of glucose instead of FA (93), while during end-stage HF the heart becomes unable to effectively utilize both substrates (94-97). During glycolysis, glucose is rapidly transformed into glucose-6-phosphate in the cytoplasm, oxidized to pyruvate and transported into the mitochondria producing ATP via the tricarboxylic acid (TCA) cycle (76). Several studies have reported that mitochondrial glucose oxidation is defective in the failing heart $(98,99)$. Elevated circulating lactate levels may be the result of increased glycolysis and the inability of the failing heart to oxidize the increased pyruvate generated from glycolysis $(98,99)$ because pyruvate dehydrogenase activity is decreased in HF (Figure 2) (90). In a rat model with compensated cardiac hypertrophy, cardiac glycolysis but not cardiac glucose oxidation was increased (100). In contrast, during compensated phases of cardiac hypertrophy in a rat model of left ventricular pressure overload, myocardial glucose oxidation rates were increased, while during decompensation of HF glucose oxidation declined (101). In hamsters with dilative cardiomyopathy (DCM) glucose-6-phosphate, fructose6-phosphate, fructose-1,6-biphosphate, malate, iso-citrate and succinate in myocardial tissues were equal to control group at 4 weeks but were all reduced at 16 weeks (102). Nowadays, it is accepted that alterations in glucose utilization may vary, depending on HF pathology and HF stage (103). This hypothesis is supported by reduced levels of circulating glucose, glucose-1-phosphate, glucose6-phosphate, lactate, citrate, succinate, succinyl-CoA and fumarate among patients with end-stage HF. After implantation of LVAD, circulating glucose and lactate levels increased in the non-failing heart (104).

\section{Amino acid metabolism}

Amino acids appear to contribute little to the overall cardiac 
energy metabolism (105). In chronic HF patients, lower circulating levels of essential and nonessential amino acids were found in the plasma, compared to patients without any history of HF (106). Optimal HF treatment partially normalized circulating levels of amino acids like cysteine, glutamate, glycine and tryptophan (107). Furthermore, several amino acids such as leucine and isoleucine can be hydrolysed and can serve as a basis to generate ketone bodies, suggesting there may be a link between ketogenic amino acids and ketone bodies in HF $(97,108,109)$. Both succinyl-CoA and ketone bodies can serve as fuel for the TCA cycle, possibly providing a beneficial effect on cardiac metabolism $(80,110)$. In patients with DCM, circulating levels of ketogenic amino acids and their metabolites where found to be significantly elevated (111). Furthermore, circulating phenylalanine and spermidine levels were increased in patients with HF, with normalization of those amino acids after HF treatment (112). Among patients with severe HF, circulating levels of phenylalanine, tyrosine, methionine, histidine, threonine, homoserine, alanine and glutamine were reduced $(104,113)$. Finally, angiotensin IIinduced cardiac hypertrophy was associated with increased myocardial levels of ketogenic lysine and tyrosine (114). However, the exact role of altered amino acid metabolism during $\mathrm{HF}$ is still unclear.

Another actor in the pathophysiology of HF development display branched-chain amino acids (BCAA). The abovementioned leucine and isoleucine plasma levels are elevated in chronic HF patients (106), irrespective of underlying obesity or dyslipidaemia. In mice, pharmacological treatment to increase cardiac BCAA catabolism resulted in delayed heart failure progression (115), suggesting that downregulation of the cardiac BCAA pathway may contribute to HF. Furthermore, BCAA may accumulate in the heart tissue, interact with insulin receptor-mediated signal transduction (116) and impair glucose processing (37). However, whether aberrant BCAA metabolism in HF patients is due to associated comorbidities such as type II diabetes and insulin resistance or a component of the metabolic signature of HF itself is still unknown. Although BCAA appear as a promising target for $\mathrm{HF}$ treatment there is also evidence of BCAAs increasing cardiac metabolic dysfunction. Branched-chain $\alpha$-keto acids suppress respiratory complex I activity leading to reduced mitochondrial respiration and elevated superoxide production ultimately resulting in reduced cardiac function and promotion of HF in the setting of left ventricular pressure overload in a murine model (117) (Figure 2).

\section{Ketone body metabolism}

Ketone bodies can be degenerated into acetyl-CoA and thus have the possibility to maintain mitochondrial respiration in the heart. Under physiological conditions ketone bodies play a minor role in the cardiac energy production, but with increasing levels of circulating ketones their contribution to energy production increases (118). However, previous studies showed the altering ability of the human heart to extract certain circulating ketone bodies, depending on presence of left ventricular dysfunction (119). Among HF patients, levels of circulating $\beta$-hydroxybutyrate and acetone were significantly increased while their concentration in the cardiac tissue was reduced (120) (Figure 2).

On the other hand, serum concentrations of ketones like acetoacetate, $\alpha$-hydroxybutyrate and $\beta$-hydroxybutyrate were lower in HFrEF patients than in patients without HF (121). Also, serum ketone levels were lower in HFrEF patients compared to HFpEF (121), potentially indicating changes in ketone metabolism depending on HF-degree. Accordingly, patients with severely reduced left ventricular function $(<35 \%)$ displayed lower plasma levels of $\beta$-hydroxybutyrate than patients with less reduced left ventricular function and healthy controls (122). Furthermore, myocardial tissues from endstage HF patients displayed higher $\beta$-hydroxybutyrylCoA levels, representing the impaired FA oxidation. Increased expressions of downstream metabolites of ketone body oxidation and contemporaneous upregulation of key enzymes in the ketone body pathway hint towards increased reliance on ketones for energy in the failing heart, compensating the decline in myocardial fatty acid oxidation (80). For example, diabetic patients in the EMPAREG outcome study, treated with a sodium-glucose cotransporter 2 inhibitor, showed a significant reduction for HF related rehospitalization. Ketone body elevation was discussed as one of the possible cardioprotective mechanisms by improving cardiac efficiency (123).

\section{Atherosclerosis}

The desire to identify individuals at great risk for atherosclerosis and consecutive ischemic heart disease has emerged over the last years. Large numbers of patients with clinically diagnosed coronary atherosclerosis present metabolic disorders in the myocardial energy production $(9,11,124)$. Common tools such as positron emission tomography (PET) to illustrate those derangements are 
expensive and are accompanied by considerable radiation exposure $(125,126)$. Hence, blood based diagnostic tools for atherosclerosis and ischemic heart disease are warranted.

Recent studies showed circulating trimethylamine$\mathrm{N}$-oxide (TMAO) to be a significant predictor for atherosclerosis and increased risk for myocardial infarction (MI) and stroke $(127,128)$. The host's gut microbiome plays a critical factor regulating the trimethylamine (TMA) production from dietary phosphatidylcholine, choline and carnitine. TMA is then released into the blood stream and converted to TMAO in the liver (129). TMAO potentially interferes with reverse cholesterol transport and thereby promotes plaque progression and increases the risk of cardiovascular events (127). TMAO might also promote platelet hyperreactivity since exogenous TMAO enhanced platelet aggregation in human platelet-rich plasma (128). Furthermore, in a mouse model of atherosclerosis, interfering with the microbiome's ability to convert dietary choline or carnitine into TMA resulted in progression of atherosclerotic lesions and reduced circulating TMAO levels (91). In conclusion, these results support the hypothesis that increased circulating levels of phosphatidylcholine or choline in combination with increased TMAO could serve as a novel biomarker for the diagnosis of coronary atherosclerosis.

Other promising biomarkers are plasma 18:2 monoglyceride, shown to be associated with higher risk, and 18:2 lysophosphatidylcholine and 28:1 sphingomyelin both shown to be associated with lower risk for future cardiovascular events (130). Increased levels of circulating arginine and decreased levels of 17:0 lysophosphatidylcholine and 18:2 lysophosphatidylcholine were associated with increased risk for MI. Predictive value of the Framingham risk score for cardiovascular disease increased significantly when combining and adding these three metabolites (131). Additionally, circulating phosphatidylcholines containing ceramide, sphingomyelin, diacylglycerol or palmitic acid were associated with increased risk of MI (132).

These lipid intermediates including ceramides and sphingomyelins are known to be accumulated in numerous tissues among obese and type 2 diabetes patients (133). Increased circulating levels of these metabolites possibly result in their increased concentration in myocardial, liver or skeletal tissue.

Finally, also circulating BCAAs (leucine/isoleucine, valine, glutamate/glutamine, proline and methionine) are shown to reflect the risk of future coronary artery disease $(10,134)$. A cross-sectional study correlated increased BCAAs with carotid intima-media thickness (as index of subclinical atherosclerosis) (135).

Summarizing, changes in these biomarkers might identify patients at risk of atherosclerosis and enable us to apply therapies earlier.

\section{Ischemic cardiomyopathy}

Coronary artery disease (CAD), despite significant improvements, remains one of the leading causes of death worldwide (136). CAD can be divided into stable and unstable angina as well as MI. Unstable angina is characterized by a critical coronary stenosis, but without following myocardial cell damage. During non-STsegment-elevation myocardial infarction (NSTEMI), this cell damage is present. ST-segment elevation myocardial infarction (STEMI) is characterized by an acute plaque rupture with following activation of plasmatic coagulation and formation of an occluding thrombus (137). During ischemic periods, oxygen and nutrition supply to the affected myocardium are markedly decreased, resulting in significant changes in the myocardial intermediary energy metabolism. Ischemic periods are characterized by a reduction in overall oxidative metabolism. To compensate this, glycolysis rates are increased. The increase in myocardial glycolysis is directly proportional to the severity and duration of ischemia (138).

\section{Fatty acid metabolism}

In the ischemic myocardium, FA oxidation rates are decreased in proportion to reduced oxygen supply, because $\beta$-oxidation of FA is dependent in oxygen for energy production (139). This was confirmed via paired collection of blood from arterial and coronary sinus blood before cardiac surgery, showing significant reduction of plasma FA in patients with CAD compared to those without CAD (140). The same experimental design showed increases in short-chain (S-C) dicarboxylacylcarnitines in $\mathrm{CAD}$ patients, predicting the risk for future cardiovascular events (126). Among patients with CAD but without heart failure, circulating medium-chain (M-S) and L-C acylcarnitines predicted subsequent cardiovascular events, independent from established predictors (141). However, their source and pathophysiology during CAD progression are unknown. One possible explanation might be the 
participation of peroxisomes in this process. Normally, L-C dicarboxylic acids are mostly oxidized in the mitochondria, while during CAD progression peroxisomal oxidation of L-C acylcarnitines could be a compensatory mechanism to metabolize straight medium- and long-chain fatty acids (142). In STEMI patients, several plasma FA were found to be increased. Among those are palmitic acid, stearic acid, linoleic acid and oleic acid, suggesting ischemiainduced alternations in cardiac energy metabolism (143). Elevated FA like eicosatertraenoic acid and eicosatrienoic acid during MI might reflect ongoing inflammation (144). The $\beta$-oxidation machinery of unsaturated FA like linoleic acid seems to be hampered during MI, contributing to myocardial ischemia $(145,146)$. Accordingly, S-C acylcarnitines were elevated and aspartic acid was reduced in patients with evident ischemia $(147,148)$. Additionally, in patients with MI, higher levels of sphingolipid pathway, sphingomyelin and ceramide were found, compared to healthy patients and patients with angina (132). These results are supported by findings in which sphinganine, an intermediate of sphingoid base biosynthesis, is upregulated during acute MI $(144,145)$. Sphingolipids and their derivates are components of cellular membranes and play an important role in vascular maturation, pathophysiology during atherosclerosis and wound healing (149). In MI, sphingolipid metabolism seems to be compromised, also resulting in increased cardiovascular diseases and obesity (150-152). Glycerophospholipids are precursors of lipid mediators and seem to be reduced during MI, namely phosphatidylserine, linoleamidoglycerophosphate choline, Lyso-PC (C18:2), Lyso-PC (C16:0), and Lyso-PC (C18:1) (145). Phosphatidylcholines can be further hydrolyzed and oxidized to prostaglandins, thromboxane and prostacyclin by cyclooxygenases and cyctochrome P450. These are all well known for their critical role during inflammation, immune response and blood pressure control (153). In summary, there is strong evidence for an altered lipid metabolism during ischemia.

\section{Glucose metabolism}

During ischemia, glucose oxidation rates are depressed, accompanied by increased glycolytic rates due to stimulated glycogenolysis $(126,154)$. Myocardial lactate concentrations rise with the severity of the ischemic period (155).

In patients with acute ischemia due to CAD or alcohol septal ablation, increased circulating lactate levels reflect enhanced myocardial anaerobic glycolytic metabolism
$(119,156)$. Interestingly, this effect is also present in patients undergoing coronary angioplasty due to stable angina. Ischemia for at least 1 minute, due to balloon inflation, resulted in increased circulating lactate levels 10 minutes later (157).

Lower oxygen levels during ischemia inhibit aerobic oxidation and fewer metabolites enter the TCA cycle leading to lower production of its intermediates such as fumarate and succinate (158-160). Reperfusion-induced production of reactive oxygen species (ROS) seems to be regulated through tissue succinate levels (161). A mouse model simulating ischemia-reperfusion injury could show that succinate accumulates in ischemic heart tissue and succinate oxidation is a key actor for mitochondrial ROS accumulation and injury (161).

\section{Amino acid metabolism}

The healthy heart's need for amino acids as ATP source is minimal as shown in isolated rat hearts where under laboratory conditions leucine oxidations contributes to $3-5 \%$ of overall cardiac oxygen consumption (162). This is supported by the finding that infusion of phenylalanine is primarily used for anabolic purposes (105). Nevertheless, it has been proposed that especially during ischemia amino acid metabolism may be important. Comparison between arteriovenous differences between CAD patients and healthy controls showed that there is a net myocardial release of alanine and uptake of glutamate in ischemic heart disease (163). Among all amino acids, glutamate might play the most important role during ischemia. Due to ischemia, cardiomyocytes' higher levels of glutamic oxaloacetic transaminase will be released into the serum, preventing the transamination of glutamate into $\alpha$-ketoglutaric acid, leading to net increase of glutamate in the ischemic tissue (164). Additionally, higher glutamate levels were shown to be associated with ongoing myocardial ischemia (165). Glutamate is able to activate ROS production, leading to inflammatory and cytotoxic cardiomyocyte death (166).

Circulating amino acids among patients who underwent coronary angiography for suspected CAD have to be shown to predict both prevalent and subsequent cardiovascular risk (167). Serum BCAA levels were elevated in sexand age-matched CAD patients versus healthy controls, independent of other "classic" risk factors such as diabetes, hypertension and hyperlipidemia (134). N-phenylacetyl-Lglutamine was upregulated in acute $\mathrm{MI}$ patients compared to patients with unstable angina, suggesting a perturbed 


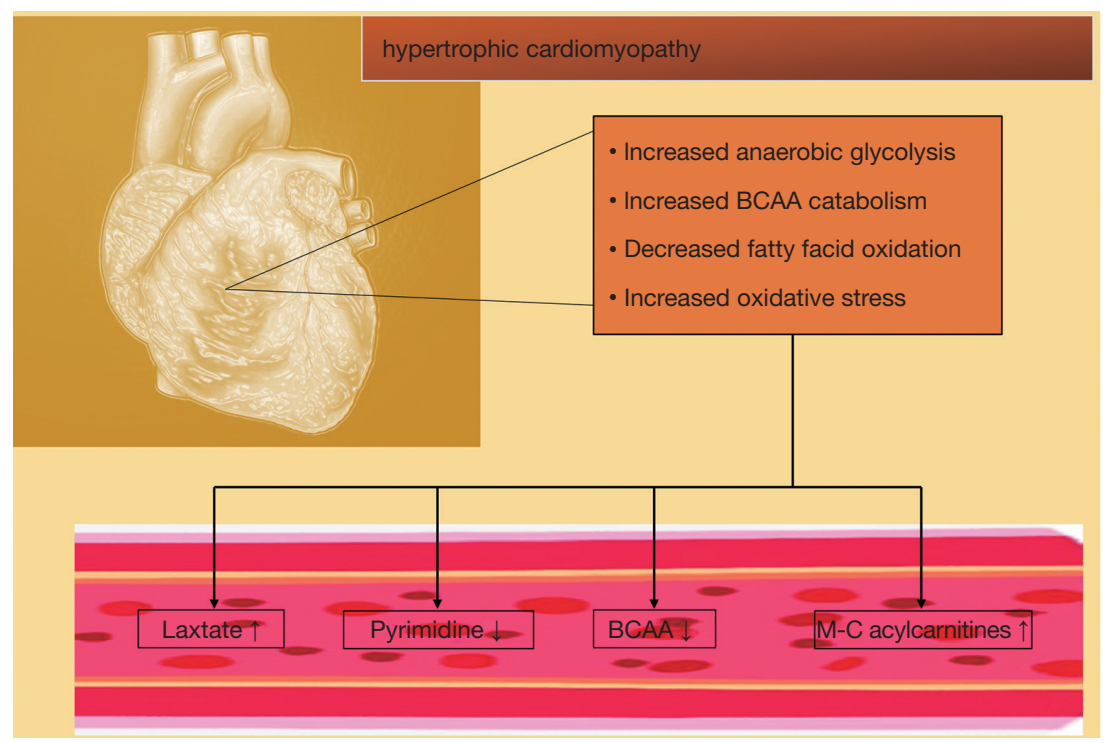

Figure 3 Hypertrophic cardiomyopathy is characterized by increased glycolysis uncoupled from glucose oxidation and accompanied by lower rates of medium-chain fatty acid oxidation. Hence, circulating metabolomic profiles often yield increases in lactate and $\mathrm{M-C}$ acylcarnitines. Furthermore, BCAA and oxidative stress metabolites are reduced in the circulation. BCAA, branch-chained amino acids; M-C, medium-chain.

phenylalanine metabolism during transition from unstable angina to acute MI (168). Furthermore, tryptophanarginine-leucine were also increased among acute MI patients suggesting activated amino acid biosynthesis as an indicator for acute MI (156).

To date, myocardial amino acid uptake seems to be of little relevance to the ischemic heart compared to other substrates (169). However, in ischemic myocardium, several amino acids like leucin, alanine and isoleucine are elevated, while others like lysine and tyrosine are degraded, compared to non-infarcted myocardium (160). This might be related to the pathophysiological mechanisms of MI. However, our knowledge about the role of amino acid and protein metabolism during the progression of ischemic heart disease remains poorly understood.

\section{Non-ischemic cardiomyopathies}

Hypertrophic cardiomyopathy (HCM) and DCM reflecting major non-ischemic cardiomyopathies are both highly prevalent monogenic diseases yet showing remarkable clinical heterogeneity (170-172). Both are characterized by disproportionate cardiac chamber growth and adjustment of ventricular wall thickness, resulting in myocyte cell apoptosis and hypertrophy, fibrosis, as well as impaired cardiac metabolism $(173,174)$.

Earlier studies identified increased glycolysis as a metabolomic hallmark of pathological HCM $(96,175)$. Furthermore, increased glycolysis is uncoupled from glucose oxidation and accompanied by lower rates of medium-chain fatty acid oxidation (176). In non-pathological HCM in contrast to pathological HCM, glucose oxidation and longchain fatty acid oxidation is increased (177). In mice with transverse aortic constriction, simulating HCM, cardiac levels of fatty acids, lysolipids, acylcarnitines and purines were upregulated in a time-dependent manner, whereas ascorbate, heme and pyrimidines were downregulated (37). Furthermore, BCAA and metabolites associated with oxidative stress and metabolic remodelling are elevated in pressure-overloaded hearts (37). Since the decompensated heart forfeits its ability to perform oxidative phosphorylation for ATP generation, there is presumably a decrease of the glucose and fatty acid flux into the TCA cycle (178). This is supported by findings of normal acylcarnitine and lactate levels in compensated HCM (179) (Figure 3). Nevertheless, these findings provide further evidence that the myocardial metabolic profile could reflect stage and aetiology of $\mathrm{HF}$.

A global metabolomic analysis of DCM-simulated hamsters via $\delta$-sarcoglycan deficiency revealed a compromised TCA cycle and glycolysis. Furthermore, DCM 


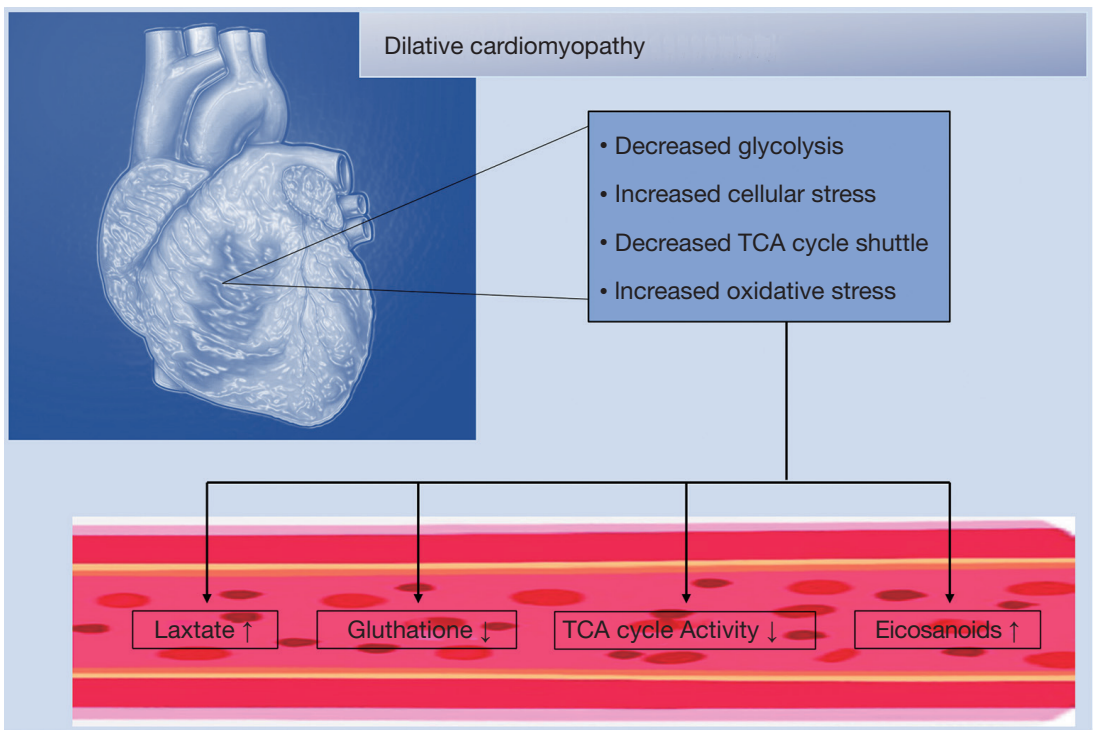

Figure 4 A hallmark of dilative cardiomyopathy is a compromised TCA cycle activity and glycolysis resulting in decreased peripheral lactate levels along with metabolites associated with oxidative stress like glutathione. Furthermore, elevated eicosanoids suggest cellular stress with consecutive activation of protective pathways with increased sphingomyelin levels. TCA, tricarboxylic acid.

hamsters suffered from altered membrane phospholipid homeostasis, glutathione biosynthesis, urea cycle and CK pathways leading to cardiac contractile dysfunction (102). Especially the decrease in glutathione and the compensatory increase in ophthalmate suggested that increased oxidative stress might play a role in DCM pathogenesis. Increasing levels of eicosanoids, ceramides and sphingomyelin suggest cellular stress and consecutive activation of protective pathways (102) (Figure 4).

Cardiac energy supply is normally dependent on fatty acids. Whether this change is a cause or a consequence of cardiac hypertrophy is still unclear. A study with mice, deficient in long-chain acyl-CoA synthetase 1 in the myocardium, revealed a switch from FA to glucose as mitochondrial fuel preference. This switch led to mechanistic target of rapamycin (mTOR)-dependent alterations in the cardiac metabolism, several genes involved in glycolysis as well as changed glutathione-related pathways and compensation by mTOR (180). Interestingly, for nutrient signalling, inhibition of autophagy and myocyte growth mTOR signalling has been reported as a central player (181).

In one study, comparing tissue DCM patients versus healthy controls decreased glycolysis, TCA cycle and malate-aspartate shuttle activities were observed (Figure 4). However, only in ischemic DCM patients an increase in ketone body oxidation and inflammatory markers was seen (182). These studies clearly indicate that a more systematic analysis of temporal changes in the cardiac metabolome among patients with ischemic and dilative cardiomyopathies is needed to reveal precise, diseasespecific signatures, and possibly filter out individuals with high risk of SCD.

\section{Current research projects}

From the perspective of translational to clinical research, prior studies evaluating metabolomics profiles in patient cohorts with cardiovascular diseases were limited in different aspects: small sample size (183-185), too much pre-specified cohorts (183), inconsistent or even unclear inclusion criteria for patient selection and control groups, usually not based on international guideline-recommendations (186), and lack of predefined prognostic endpoints as demanded by these guidelines (187-189).

For example, DeFilippis et al. developed criteria for differentiating of thrombotic and non-thrombotic myocardial infarction (184). Other studies divided patients in normal coronary arteries, non-obstructive coronary arteries, stable angina, non-stable angina as well as acute myocardial infarction, irrespective of the international universal definitions of myocardial infarction (144). Therefore, clearly 
predefined patient cohorts based on disease consensus documents are needed when investigating targeted metabolomic approaches in patients with cardiovascular diseases $(190,191)$. To translate differential diagnostic finding by identifying significant metabolomics clusters, hard clinical endpoints in terms of prognosis, such as allcause and cardiovascular mortality or heart failure related rehopsitalization need to assessed $(144,191,192)$.

Therefore, we recently investigated in pragmatic research project to counterbalance these inconsistencies of metabolomics studies. The "Metabolomics and Microbiomic in Cardiovascular Diseases" (MEMORIA) study evaluates guideline-conform patient cohorts including mid-term and long-term follow-up periods (from 6 to 24 months) [https:// clinicaltrials.gov/ct2/show/NCT04146701]. Cardiovascular disease cohorts will include a total of 800 patients with acute heart failure, acute myocardial infarction, such as non-ST and ST segment elevation myocardial infarction, chronic heart failure due to progressive non-ischemic and ischemic cardiomyopathies and the impact of implanted cardioverter defibrillator (ICD), well as sepsis or septic shock. Prognostic endpoints are all-cause and cardiovascular mortality, heart-failure related rehospitalization, stroke, recurrent myocardial infarction, ventricular tachyarrhythmias, quality of life. MEMORIA aims to close the gap between preliminary to clinically relevant research of targeted metabolomics in cardiovascular diseases.

\section{Conclusions and future implications}

New -omics platforms such as metabolomics provide great opportunities to gain further insights into cardiovascular disease risk and pathogenesis. Because most patients with cardiovascular diseases additionally suffer from associated comorbidities like chronic kidney disease, obesity or diabetes, metabolomics, in particular, has improved the understanding of the molecular principals of these conditions. Furthermore, metabolomics provide a functional integration of upstream genetic, transcriptomic and proteomic variations in combination with environmental factors, thus reflecting molecular processes more proximal to the respective disease state. Because clinically confounding factors like diet, age, sex and drug effects influence results and conclusions, application of metabolomic profiling of large population-based epidemiological cohorts has allowed statistical adjustment for potential confounders for future analyses $(9,193)$. In parallel, advances in computational analyses have to continue to provide an integration of various-omics data sets to gain a more comprehensive view of molecular mechanisms of cardiovascular disease. Summarizing, metabolomics constitutes a further step towards a personalized medicine enabling us to predict, detect and understand a multitude of cardiovascular disease states.

\section{Acknowledgments}

Funding: The MEMORIA study is supported by a grant of Heuer foundation of medical research in Germany.

\section{Footnote}

Reporting Checklist: The authors have completed the Narrative Review reporting checklist. Available at http:// dx.doi.org/10.21037/jtd-21-22

Peer Review File: Available at http://dx.doi.org/10.21037/ jtd-21-22

Conflicts of Interest: All authors have completed the ICMJE uniform disclosure form (available at http://dx.doi. org/10.21037/jtd-21-22). The authors have no conflicts of interest to declare.

Ethical Statement: The authors are accountable for all aspects of the work in ensuring that questions related to the accuracy or integrity of any part of the work are appropriately investigated and resolved.

Open Access Statement: This is an Open Access article distributed in accordance with the Creative Commons Attribution-NonCommercial-NoDerivs 4.0 International License (CC BY-NC-ND 4.0), which permits the noncommercial replication and distribution of the article with the strict proviso that no changes or edits are made and the original work is properly cited (including links to both the formal publication through the relevant DOI and the license). See: https://creativecommons.org/licenses/by-nc-nd/4.0/.

\section{References}

1. van Bilsen M, van Nieuwenhoven FA, van der Vusse GJ. Metabolic remodelling of the failing heart: beneficial or detrimental? Cardiovasc Res 2009;81:420-8.

2. Smith CS, Bottomley PA, Schulman SP, et al. Altered creatine kinase adenosine triphosphate kinetics in 
failing hypertrophied human myocardium. Circulation 2006; 114:1151-8.

3. Nascimben L, Ingwall JS, Pauletto P, et al. Creatine kinase system in failing and nonfailing human myocardium. Circulation 1996;94:1894-901.

4. Roberts LD, Gerszten RE. Toward new biomarkers of cardiometabolic diseases. Cell Metab 2013;18:43-50.

5. Lewis GD, Asnani A, Gerszten RE. Application of metabolomics to cardiovascular biomarker and pathway discovery. J Am Coll Cardiol 2008;52:117-23.

6. Raamsdonk LM, Teusink B, Broadhurst D, et al. A functional genomics strategy that uses metabolome data to reveal the phenotype of silent mutations. Nat Biotechnol 2001;19:45-50.

7. Bujak R, Struck-Lewicka W, Markuszewski MJ, et al. Metabolomics for laboratory diagnostics. J Pharm Biomed Anal 2015;113:108-20.

8. Kind T, Wohlgemuth G, Lee DY, et al. FiehnLib: mass spectral and retention index libraries for metabolomics based on quadrupole and time-of-flight gas chromatography/mass spectrometry. Anal Chem 2009;81:10038-48.

9. Kirschenlohr HL, Griffin JL, Clarke SC, et al. Proton NMR analysis of plasma is a weak predictor of coronary artery disease. Nat Med 2006;12:705-10.

10. Shah SH, Bain JR, Muehlbauer MJ, et al. Association of a peripheral blood metabolic profile with coronary artery disease and risk of subsequent cardiovascular events. Circ Cardiovasc Genet 2010;3:207-14.

11. Brindle JT, Antti H, Holmes E, et al. Rapid and noninvasive diagnosis of the presence and severity of coronary heart disease using $1 \mathrm{H}-\mathrm{NMR}$-based metabonomics. Nat Med 2002;8:1439-44.

12. Taegtmeyer H, Young ME, Lopaschuk GD, et al. Assessing Cardiac Metabolism: A Scientific Statement From the American Heart Association. Circ Res 2016;118:1659-701.

13. Brennan L. NMR-based metabolomics: from sample preparation to applications in nutrition research. Prog Nucl Magn Reson Spectrosc 2014;83:42-9.

14. Mayr M, Yusuf S, Weir G, et al. Combined Metabolomic and Proteomic Analysis of Human Atrial Fibrillation. J Am Coll Cardiol 2008;51:585-94.

15. Griffin JL, Williams HJ, Sang E, et al. Metabolic Profiling of Genetic Disorders: A Multitissue 1H Nuclear Magnetic Resonance Spectroscopic and Pattern Recognition Study into Dystrophic Tissue. Anal Biochem 2001;293:16-21.

16. Griffin JL, Castro C. NMR-Based Metabolomics in Cardiac Research. Methods Mol Biol 2019;2037:189-94.
17. Domingo-Almenara X, Brezmes J, Vinaixa M, et al. eRah: A Computational Tool Integrating Spectral Deconvolution and Alignment with Quantification and Identification of Metabolites in GC/MS-Based Metabolomics. Anal Chem 2016;88:9821-9.

18. Clos LJ, 2nd, Jofre MF, Ellinger JJ, et al. NMRbot: Python scripts enable high-throughput data collection on current Bruker BioSpin NMR spectrometers. Metabolomics 2013;9:558-63.

19. Tulpan D, Léger S, Belliveau L, et al. MetaboHunter: an automatic approach for identification of metabolites from 1H-NMR spectra of complex mixtures. BMC Bioinformatics 2011;12:400.

20. Atherton HJ, Gulston MK, Bailey NJ, et al. Metabolomics of the interaction between PPAR-alpha and age in the PPAR-alpha-null mouse. Mol Syst Biol 2009;5:259.

21. Gil M, Samino S, Barrilero R, et al. Lipid Profiling Using (1)H NMR Spectroscopy. Methods Mol Biol 2019;2037:35-47.

22. Chylla RA, Hu K, Ellinger JJ, et al. Deconvolution of twodimensional NMR spectra by fast maximum likelihood reconstruction: application to quantitative metabolomics. Anal Chem 2011;83:4871-80.

23. Clendinen CS, Stupp GS, Wang B, et al. (13) C Metabolomics: NMR and IROA for Unknown Identification. Curr Metabolomics 2016;4:116-20.

24. Shah SH, Kraus WE, Newgard CB. Metabolomic profiling for the identification of novel biomarkers and mechanisms related to common cardiovascular diseases: form and function. Circulation 2012;126:1110-20.

25. Nicholson JK, Lindon JC. Systems biology: Metabonomics. Nature 2008;455:1054-6.

26. Exarchou V, Krucker M, van Beek TA, et al. LCNMR coupling technology: recent advancements and applications in natural products analysis. Magn Reson Chem 2005;43:681-7.

27. Tokunaga T, Akagi KI, Okamoto M. Sensitivity enhancement by chromatographic peak concentration with ultra-high performance liquid chromatography-nuclear magnetic resonance spectroscopy for minor impurity analysis. J Chromatogr A 2017;1508:163-8.

28. Kitamaki Y, Saito N, Yamazaki T, et al. Determination of PAHs in Solution with a Single Reference Standard by a Combination of 1H Quantitative NMR Spectroscopy and Chromatography. Anal Chem 2017;89:6963-8.

29. Hu Q, Noll RJ, Li H, et al. The Orbitrap: a new mass spectrometer. J Mass Spectrom 2005;40:430-43.

30. Prodhan MAI, Shi B, Song M, et al. Integrating 
comprehensive two-dimensional gas chromatography mass spectrometry and parallel two-dimensional liquid chromatography mass spectrometry for untargeted metabolomics. Analyst 2019;144:4331-41.

31. Kanani HH, Klapa MI. Data correction strategy for metabolomics analysis using gas chromatography-mass spectrometry. Metab Eng 2007;9:39-51.

32. Spagou K, Theodoridis G, Wilson I, et al. A GC-MS metabolic profiling study of plasma samples from mice on low- and high-fat diets. J Chromatogr B Analyt Technol Biomed Life Sci 2011;879:1467-75.

33. Misra BB, Bassey E, Bishop AC, et al. High-resolution gas chromatography/mass spectrometry metabolomics of nonhuman primate serum. Rapid Commun Mass Spectrom 2018;32:1497-506.

34. Alsaleh M, Barbera TA, Andrews RH, et al. Mass Spectrometry: A Guide for the Clinician. J Clin Exp Hepatol 2019;9:597-606.

35. Yao L, Sheflin AM, Broeckling CD, et al. Data Processing for GC-MS- and LC-MS-Based Untargeted Metabolomics. Methods Mol Biol 2019;1978:287-99.

36. Kayacelebi AA, Beckmann B, Gutzki FM, et al. GC-MS and GC-MS/MS measurement of the cardiovascular risk factor homoarginine in biological samples. Amino Acids 2014;46:2205-17.

37. Sansbury BE, DeMartino AM, Xie Z, et al. Metabolomic analysis of pressure-overloaded and infarcted mouse hearts. Circ Heart Fail 2014;7:634-42.

38. Tranchida PQ, Salivo S, Franchina FA, et al. FlowModulated Comprehensive Two-Dimensional Gas Chromatography Combined with a High-Resolution Time-of-Flight Mass Spectrometer: A Proof-of-Principle Study. Anal Chem 2015;87:2925-30.

39. Zhu L, Zhou J, Liang C, et al. Retention time bracketing for targeted sphingolipidomics by liquid chromatographytandem mass spectrometry. Bioanalysis 2019;11:185-201.

40. Wu Q, Xu Y, Ji H, et al. Enhancing coverage in LCMS-based untargeted metabolomics by a new sample preparation procedure using mixed-mode solid-phase extraction and two derivatizations. Analytical and BioAnal Chem 2019;411:6189-202.

41. Gika H, Virgiliou C, Theodoridis G, et al. Untargeted LC/MS-based metabolic phenotyping (metabonomics/ metabolomics): The state of the art. J Chromatogr B Analyt Technol Biomed Life Sci 2019;1117:136-47.

42. McGarrah RW, Crown SB, Zhang GF, et al. Cardiovascular Metabolomics. Circ Res 2018;122:1238-58.

43. Fiehn O. Metabolomics by Gas Chromatography-Mass
Spectrometry: Combined Targeted and Untargeted

Profiling. Curr Protoc Mol Biol. 2016;114:30.4.1-30.4.32.

44. Taegtmeyer H, Golfman L, Sharma S, et al. Linking gene expression to function: metabolic flexibility in the normal and diseased heart. Ann N Y Acad Sci 2004;1015:202-13.

45. Ingwall J. ATP and the Heart. Boston: Kluwer Academic Publishers, 2002.

46. Neubauer S. The failing heart--an engine out of fuel. $\mathrm{N}$ Engl J Med 2007;356:1140-51.

47. Randle PJ, Garland PB, Hales CN, et al. The glucose fatty-acid cycle. Its role in insulin sensitivity and the metabolic disturbances of diabetes mellitus. Lancet 1963;1:785-9.

48. Dávila-Román VG, Vedala G, Herrero P, et al. Altered myocardial fatty acid and glucose metabolism in idiopathic dilated cardiomyopathy. J Am Coll Cardiol 2002;40:271-7.

49. Razeghi P, Young ME, Alcorn JL, et al. Metabolic gene expression in fetal and failing human heart. Circulation 2001;104:2923-31.

50. Herrmann G, Decherd Jr GM. The chemical nature of heart failure. Ann Inter Med 1939;12:1233-44.

51. Olson RE. Myocardial metabolism in congestive heart failure. J Chronic Dis 1959;9:442-64.

52. Olson RE, Schwartz WB. Myocardial metabolism in congestive heart failure. Medicine 1951;30:21-41.

53. Pfeffer MA, Braunwald E, Moyé LA, et al. Effect of captopril on mortality and morbidity in patients with left ventricular dysfunction after myocardial infarction. Results of the survival and ventricular enlargement trial. The SAVE Investigators. N Engl J Med 1992;327:669-77.

54. CONSENSUS Trial Study Group. Effects of enalapril on mortality in severe congestive heart failure. Results of the Cooperative North Scandinavian Enalapril Survival Study (CONSENSUS). N Engl J Med 1987;316:1429-35.

55. Packer M, Bristow MR, Cohn JN, et al. The effect of carvedilol on morbidity and mortality in patients with chronic heart failure. U.S. Carvedilol Heart Failure Study Group. N Engl J Med 1996;334:1349-55.

56. A randomized trial of beta-blockade in heart failure. The Cardiac Insufficiency Bisoprolol Study (CIBIS). CIBIS Investigators and Committees. Circulation 1994;90:1765-73.

57. Cohn JN, Tognoni G. A randomized trial of the angiotensin-receptor blocker valsartan in chronic heart failure. N Engl J Med 2001;345:1667-75.

58. Pfeffer MA, Swedberg K, Granger CB, et al. Effects of candesartan on mortality and morbidity in patients with chronic heart failure: the CHARM-Overall programme. 
Lancet 2003;362:759-66.

59. Taegtmeyer H. Cardiac metabolism as a target for the treatment of heart failure. Circulation 2004;110:894-6.

60. Wallimann T. Bioenergetics. Dissecting the role of creatine kinase. Curr Biol 1994;4:42-6.

61. Ingwall JS, Atkinson DE, Clarke K, Fetters JK. Energetic correlates of cardiac failure: changes in the creatine kinase system in the failing myocardium. Eur Heart J. 1990;11 Suppl B:108-15.

62. Saks VA, Lipina NV, Smirnov VN, et al. Studies of energy transport in heart cells. The functional coupling between mitochondrial creatine phosphokinase and ATP ADP translocase: kinetic evidence. Arch Biochem Biophys 1976;173:34-41.

63. Neubauer S, Krahe T, Schindler R, et al. 31P magnetic resonance spectroscopy in dilated cardiomyopathy and coronary artery disease. Altered cardiac high-energy phosphate metabolism in heart failure. Circulation 1992;86:1810-8.

64. Neubauer S, Horn M, Pabst T, et al. Contributions of 31P-magnetic resonance spectroscopy to the understanding of dilated heart muscle disease. Eur Heart J 1995;16 Suppl O:115-8.

65. Lamb HJ, Beyerbacht HP, van der Laarse A, et al. Diastolic dysfunction in hypertensive heart disease is associated with altered myocardial metabolism. Circulation 1999;99:2261-7.

66. Ten Hove M, Chan S, Lygate C, et al. Mechanisms of creatine depletion in chronically failing rat heart. J Mol Cell Cardiol 2005;38:309-13.

67. Wallis J, Lygate CA, Fischer A, et al. Supranormal myocardial creatine and phosphocreatine concentrations lead to cardiac hypertrophy and heart failure: insights from creatine transporter-overexpressing transgenic mice. Circulation 2005;112:3131-9.

68. Dorn GW, 2nd, Maack C. SR and mitochondria: calcium cross-talk between kissing cousins. J Mol Cell Cardiol 2013;55:42-9.

69. Marx SO, Marks AR. Dysfunctional ryanodine receptors in the heart: new insights into complex cardiovascular diseases. J Mol Cell Cardiol 2013;58:225-31.

70. Hasenfuss G, Schillinger W, Lehnart SE, et al. Relationship between $\mathrm{Na}$ +- $\mathrm{Ca} 2+-$ exchanger protein levels and diastolic function of failing human myocardium. Circulation 1999;99:641-8.

71. Pogwizd SM, Schlotthauer K, Li L, et al. Arrhythmogenesis and contractile dysfunction in heart failure: Roles of sodium-calcium exchange, inward rectifier potassium current, and residual beta-adrenergic responsiveness. Circ Res 2001;88:1159-67.

72. Wier WG, Balke $\mathrm{CW}$. $\mathrm{Ca}(2+)$ release mechanisms, $\mathrm{Ca}(2+)$ sparks, and local control of excitation-contraction coupling in normal heart muscle. Circ Res 1999;85:770-6.

73. Liu T, O'Rourke B. Enhancing mitochondrial Ca2+ uptake in myocytes from failing hearts restores energy supply and demand matching. Circ Res 2008;103:279-88.

74. Murgia M, Giorgi C, Pinton P, et al. Controlling metabolism and cell death: at the heart of mitochondrial calcium signalling. J Mol Cell Cardiol 2009;46:781-8.

75. Kohlhaas M, Maack C. Adverse bioenergetic consequences of $\mathrm{Na}+-\mathrm{Ca} 2+$ exchanger-mediated $\mathrm{Ca} 2+$ influx in cardiac myocytes. Circulation 2010;122:2273-80.

76. Schwenk RW, Luiken JJ, Bonen A, et al. Regulation of sarcolemmal glucose and fatty acid transporters in cardiac disease. Cardiovasc Res 2008;79:249-58.

77. Bain JR, Stevens RD, Wenner BR, et al. Metabolomics applied to diabetes research: moving from information to knowledge. Diabetes 2009;58:2429-43.

78. Ahmad T, Kelly JP, McGarrah RW, et al. Prognostic Implications of Long-Chain Acylcarnitines in Heart Failure and Reversibility With Mechanical Circulatory Support. J Am Coll Cardiol 2016;67:291-9.

79. Hunter WG, Kelly JP, McGarrah RW 3rd, et al. Metabolomic Profiling Identifies Novel Circulating Biomarkers of Mitochondrial Dysfunction Differentially Elevated in Heart Failure With Preserved Versus Reduced Ejection Fraction: Evidence for Shared Metabolic Impairments in Clinical Heart Failure. J Am Heart Assoc 2016;5:e003190.

80. Bedi KC Jr, Snyder NW, Brandimarto J, et al. Evidence for Intramyocardial Disruption of Lipid Metabolism and Increased Myocardial Ketone Utilization in Advanced Human Heart Failure. Circulation 2016;133:706-16.

81. Mihalik SJ, Goodpaster BH, Kelley DE, et al. Increased levels of plasma acylcarnitines in obesity and type 2 diabetes and identification of a marker of glucolipotoxicity. Obesity (Silver Spring) 2010;18:1695-700.

82. Lopaschuk GD, Ussher JR, Folmes CD, et al. Myocardial fatty acid metabolism in health and disease. Physiol Rev 2010;90:207-58.

83. Rosenblatt-Velin N, Montessuit C, Papageorgiou I, et al. Postinfarction heart failure in rats is associated with upregulation of GLUT-1 and downregulation of genes of fatty acid metabolism. Cardiovasc Res 2001;52:407-16.

84. Sack MN, Rader TA, Park S, et al. Fatty acid oxidation enzyme gene expression is downregulated in the failing 
heart. Circulation 1996;94:2837-42.

85. Lommi J, Kupari M, Yki-Järvinen H. Free fatty acid kinetics and oxidation in congestive heart failure. Am J Cardiol 1998;81:45-50.

86. Lommi J, Kupari M, Koskinen P, et al. Blood ketone bodies in congestive heart failure. J Am Coll Cardiol 1996;28:665-72.

87. Allard MF, Schonekess BO, Henning SL, et al. Contribution of oxidative metabolism and glycolysis to ATP production in hypertrophied hearts. Am J Physiol 1994;267:H742-50.

88. Christian B, El Alaoui-Talibi Z, Moravec M, et al. Palmitate oxidation by the mitochondria from volumeoverloaded rat hearts. Mol Cell Biochem 1998;180:117-28.

89. Christe ME, Rodgers RL. Altered glucose and fatty acid oxidation in hearts of the spontaneously hypertensive rat. J Mol Cell Cardiol 1994;26:1371-5.

90. Ussher JR, Elmariah S, Gerszten RE, et al. The Emerging Role of Metabolomics in the Diagnosis and Prognosis of Cardiovascular Disease. J Am Coll Cardiol 2016;68:2850-70.

91. Wang Z, Roberts AB, Buffa JA, et al. Non-lethal Inhibition of Gut Microbial Trimethylamine Production for the Treatment of Atherosclerosis. Cell 2015;163:1585-95.

92. Robinson R, Robinson LJ, James DE, et al. Glucose transport in L6 myoblasts overexpressing GLUT1 and GLUT4. J Biol Chem 1993;268:22119-26.

93. Nascimben L, Ingwall JS, Lorell BH, et al. Mechanisms for increased glycolysis in the hypertrophied rat heart. Hypertension 2004;44:662-7.

94. Osorio JC, Stanley WC, Linke A, et al. Impaired myocardial fatty acid oxidation and reduced protein expression of retinoid $\mathrm{X}$ receptor-alpha in pacing-induced heart failure. Circulation 2002;106:606-12.

95. Luptak I, Balschi JA, Xing Y, et al. Decreased contractile and metabolic reserve in peroxisome proliferatoractivated receptor-alpha-null hearts can be rescued by increasing glucose transport and utilization. Circulation 2005;112:2339-46.

96. Sorokina N, O'Donnell JM, McKinney RD, et al. Recruitment of compensatory pathways to sustain oxidative flux with reduced carnitine palmitoyltransferase I activity characterizes inefficiency in energy metabolism in hypertrophied hearts. Circulation 2007;115:2033-41.

97. O'Donnell JM, Fields AD, Sorokina N, et al. The absence of endogenous lipid oxidation in early stage heart failure exposes limits in lipid storage and turnover. J Mol Cell Cardiol 2008;44:315-22.
98. Stanley WC, Recchia FA, Lopaschuk GD. Myocardial substrate metabolism in the normal and failing heart. Physiol Rev 2005;85:1093-129.

99. Gupte AA, Hamilton DJ, Cordero-Reyes AM, et al. Mechanical unloading promotes myocardial energy recovery in human heart failure. Circ Cardiovasc Genet 2014;7:266-76.

100. Degens H, de Brouwer KF, Gilde AJ, et al. Cardiac fatty acid metabolism is preserved in the compensated hypertrophic rat heart. Basic Res Cardiol 2006;101:17-26.

101. Doenst T, Pytel G, Schrepper A, et al. Decreased rates of substrate oxidation ex vivo predict the onset of heart failure and contractile dysfunction in rats with pressure overload. Cardiovasc Res 2010;86:461-70.

102. Maekawa K, Hirayama A, Iwata Y, et al. Global metabolomic analysis of heart tissue in a hamster model for dilated cardiomyopathy. J Mol Cell Cardiol 2013;59:76-85.

103. Doenst T, Nguyen TD, Abel ED. Cardiac metabolism in heart failure: implications beyond ATP production. Circ Res 2013;113:709-24.

104.Diakos NA, Navankasattusas S, Abel ED, et al. Evidence of Glycolysis Up-Regulation and Pyruvate Mitochondrial Oxidation Mismatch During Mechanical Unloading of the Failing Human Heart: Implications for Cardiac Reloading and Conditioning. JACC Basic Transl Sci 2016;1:432-44.

105. Young LH, McNulty PH, Morgan C, et al. Myocardial protein turnover in patients with coronary artery disease. Effect of branched chain amino acid infusion. J Clin Invest 1991;87:554-60.

106. Wang J, Li Z, Chen J, et al. Metabolomic identification of diagnostic plasma biomarkers in humans with chronic heart failure. Mol Biosyst 2013;9:2618-26.

107. Nemutlu E, Zhang S, Xu YZ, et al. Cardiac resynchronization therapy induces adaptive metabolic transitions in the metabolomic profile of heart failure. J Card Fail 2015;21:460-9.

108. Turer AT. Using metabolomics to assess myocardial metabolism and energetics in heart failure. J Mol Cell Cardiol 2013;55:12-8.

109. Mervaala E, Biala A, Merasto S, et al. Metabolomics in angiotensin II-induced cardiac hypertrophy. Hypertension 2010;5 5:508-15.

110.Aubert G, Martin OJ, Horton JL, et al. The Failing Heart Relies on Ketone Bodies as a Fuel. Circulation 2016;133:698-705.

111.Alexander D, Lombardi R, Rodriguez G, et al. Metabolomic distinction and insights into the pathogenesis of human primary dilated cardiomyopathy. Eur J Clin 
Invest 2011;41:527-38.

112. Cheng ML, Wang CH, Shiao MS, et al. Metabolic disturbances identified in plasma are associated with outcomes in patients with heart failure: diagnostic and prognostic value of metabolomics. J Am Coll Cardiol 2015;65:1509-20.

113. Weitzel LB, Ambardekar AV, Brieke A, et al. Left ventricular assist device effects on metabolic substrates in the failing heart. PLoS One 2013;8:e60292.

114. Mervaala E, Biala A, Merasto S, et al. Metabolomics in angiotensin II-induced cardiac hypertrophy. Hypertension 2010;55:508-15.

115.Wang W, Zhang F, Xia Y, et al. Defective branched chain amino acid catabolism contributes to cardiac dysfunction and remodeling following myocardial infarction. Am J Physiol Heart Circ Physiol 2016;311:H1160-9.

116. Lynch CJ, Adams SH. Branched-chain amino acids in metabolic signalling and insulin resistance. Nat Rev Endocrinol 2014;10:723-36.

117.Sun H, Olson KC, Gao C, et al. Catabolic Defect of Branched-Chain Amino Acids Promotes Heart Failure. Circulation 2016;133:2038-49.

118. Ho KL, Zhang L, Wagg C, et al. Increased ketone body oxidation provides additional energy for the failing heart without improving cardiac efficiency. Cardiovasc Res 2019;115:1606-16.

119. Turer AT, Stevens RD, Bain JR, et al. Metabolomic profiling reveals distinct patterns of myocardial substrate use in humans with coronary artery disease or left ventricular dysfunction during surgical ischemia/ reperfusion. Circulation 2009;119:1736-46.

120.Du Z, Shen A, Huang Y, et al. 1H-NMR-based metabolic analysis of human serum reveals novel markers of myocardial energy expenditure in heart failure patients. PLoS One 2014;9:e88102.

121.Zordoky BN, Sung MM, Ezekowitz J, et al. Metabolomic fingerprint of heart failure with preserved ejection fraction. PLoS One 2015;10:e0124844.

122.Deidda M, Piras C, Dessalvi CC, et al. Metabolomic approach to profile functional and metabolic changes in heart failure. J Transl Med 2015;13:297.

123.Mudaliar S, Alloju S, Henry RR. Can a Shift in Fuel Energetics Explain the Beneficial Cardiorenal Outcomes in the EMPA-REG OUTCOME Study? A Unifying Hypothesis. Diabetes Care 2016;39:1115-22.

124. Sabatine MS, Liu E, Morrow DA, et al. Metabolomic identification of novel biomarkers of myocardial ischemia. Circulation 2005;112:3868-75.
125. Kisrieva-Ware Z, Coggan AR, Sharp TL, et al. Assessment of myocardial triglyceride oxidation with PET and 11C-palmitate. J Nucl Cardiol 2009;16:411-21.

126. Wisneski JA, Gertz EW, Neese RA, et al. Myocardial metabolism of free fatty acids. Studies with 14C-labeled substrates in humans. J Clin Invest 1987;79:359-66.

127. Tang WH, Hazen SL. The contributory role of gut microbiota in cardiovascular disease. J Clin Invest 2014;124:4204-11.

128.Zhu W, Gregory JC, Org E, et al. Gut Microbial Metabolite TMAO Enhances Platelet Hyperreactivity and Thrombosis Risk. Cell 2016;165:111-24.

129. Hoyles L, Jiménez-Pranteda ML, Chilloux J, et al. Metabolic retroconversion of trimethylamine $\mathrm{N}$-oxide and the gut microbiota. Microbiome 2018;6:73.

130. Ganna A, Salihovic S, Sundstrom J, et al. Large-scale metabolomic profiling identifies novel biomarkers for incident coronary heart disease. PLoS Genet 2014;10:e1004801.

131.Ward-Caviness CK, Xu T, Aspelund T, et al. Improvement of myocardial infarction risk prediction via inflammation-associated metabolite biomarkers. Heart 2017;103:1278-85.

132.Park JY, Lee SH, Shin MJ, et al. Alteration in metabolic signature and lipid metabolism in patients with angina pectoris and myocardial infarction. PLoS One 2015;10:e0135228.

133. Muoio DM, Newgard CB. Mechanisms of disease: Molecular and metabolic mechanisms of insulin resistance and beta-cell failure in type 2 diabetes. Nat Rev Mol Cell Biol 2008;9:193-205.

134. Yang RY, Wang SM, Sun L, et al. Association of branchedchain amino acids with coronary artery disease: A matched-pair case-control study. Nutr Metab Cardiovasc Dis 2015;25:937-42.

135. Yang R, Dong J, Zhao H, et al. Association of branchedchain amino acids with carotid intima-media thickness and coronary artery disease risk factors. PLoS One 2014;9:e99598.

136.GBD 2013 Mortality and Causes of Death Collaborators. Global, regional, and national age-sex specific all-cause and cause-specific mortality for 240 causes of death, 19902013: a systematic analysis for the Global Burden of Disease Study 2013. Lancet 2015;385:117-71.

137. Thygesen K, Alpert JS, Jaffe AS, et al. Fourth universal definition of myocardial infarction (2018). Eur Heart J 2019;40:237-69.

138. Stanley WC, Lopaschuk GD, Hall JL, et al. Regulation 
of myocardial carbohydrate metabolism under normal and ischaemic conditions. Potential for pharmacological interventions. Cardiovasc Res 1997;33:243-57.

139. Lloyd SG, Wang P, Zeng H, et al. Impact of low-flow ischemia on substrate oxidation and glycolysis in the isolated perfused rat heart. Am J Physiol Heart Circ Physiol 2004;287:H351-62.

140. Folmes CD, Sowah D, Clanachan AS, et al. High rates of residual fatty acid oxidation during mild ischemia decrease cardiac work and efficiency. J Mol Cell Cardiol 2009;47:142-8.

141. Rizza S, Copetti M, Rossi C, et al. Metabolomics signature improves the prediction of cardiovascular events in elderly subjects. Atherosclerosis 2014;232:260-4.

142. Shah SH, Newgard CB. Integrated metabolomics and genomics: systems approaches to biomarkers and mechanisms of cardiovascular disease. Circ Cardiovasc Genet 2015;8:410-9.

143. Ali SE, Farag MA, Holvoet P, et al. A Comparative Metabolomics Approach Reveals Early Biomarkers for Metabolic Response to Acute Myocardial Infarction. Sci Rep 2016;6:36359.

144. Fan Y, Li Y, Chen Y, et al. Comprehensive Metabolomic Characterization of Coronary Artery Diseases. J Am Coll Cardiol 2016;68:1281-93.

145.Zhu M, Han Y, Zhang Y, et al. Metabolomics Study of the Biochemical Changes in the Plasma of Myocardial Infarction Patients. Front Physiol 2018;9:1017.

146. Hjelte LE, Nilsson A. Arachidonic acid and ischemic heart disease. J Nutr 2005;135:2271-3.

147. Koves TR, Ussher JR, Noland RC, et al. Mitochondrial overload and incomplete fatty acid oxidation contribute to skeletal muscle insulin resistance. Cell Metab 2008;7:45-56.

148. Lazo M, Rubin J, Clark JM, et al. The association of liver enzymes with biomarkers of subclinical myocardial damage and structural heart disease. J Hepatol 2015;62:841-7.

149. Watterson K, Sankala H, Milstien S, et al. Pleiotropic actions of sphingosine-1-phosphate. Prog Lipid Res 2003;42:344-57.

150. Wymann MP, Schneiter R. Lipid signalling in disease. Nat Rev Mol Cell Biol 2008;9:162-76.

151. Hadas Y, Vincek AS, Youssef E, et al. Altering Sphingolipid Metabolism Attenuates Cell Death and Inflammatory Response After Myocardial Infarction. Circulation 2020;141:916-30.

152.Knapp M, Zendzian-Piotrowska M, Błachnio-Zabielska A, et al. Myocardial infarction differentially alters sphingolipid levels in plasma, erythrocytes and platelets of the rat. Basic Res Cardiol 2012;107:294.

153. Dennis EA, Norris PC. Eicosanoid storm in infection and inflammation. Nat Rev Immunol 2015;15:511-23.

154. Vary TC, Reibel DK, Neely JR. Control of energy metabolism of heart muscle. Annu Rev Physiol 1981;43:419-30.

155. Neely JR, Rovetto MJ, Whitmer JT, et al. Effects of ischemia on function and metabolism of the isolated working rat heart. Am J Physiol 1973;225:651-8.

156.Lewis GD, Wei R, Liu E, et al. Metabolite profiling of blood from individuals undergoing planned myocardial infarction reveals early markers of myocardial injury. J Clin Invest 2008;118:3503-12.

157. Bodi V, Sanchis J, Morales JM, et al. Metabolomic profile of human myocardial ischemia by nuclear magnetic resonance spectroscopy of peripheral blood serum: a translational study based on transient coronary occlusion models. J Am Coll Cardiol 2012;59:1629-41.

158.Li F, Xu Q, Zheng T, et al. Metabonomic analysis of Allium macrostemon Bunge as a treatment for acute myocardial ischemia in rats. J Pharm Biomed Anal 2014;88:225-34.

159. Mohamad N, Ismet RI, Rofiee M, et al. Metabolomics and partial least square discriminant analysis to predict history of myocardial infarction of self-claimed healthy subjects: validity and feasibility for clinical practice. J Clin Bioinforma 2015;5:3.

160. Wang X, Wang D, Wu J, et al. Metabolic Characterization of Myocardial Infarction Using GC-MS-Based Tissue Metabolomics. Int Heart J 2017;58:441-6.

161. Chouchani ET, Pell VR, Gaude E, et al. Ischaemic accumulation of succinate controls reperfusion injury through mitochondrial ROS. Nature 2014;515:431-5.

162.Ichihara K, Neely JR, Siehl DL, et al. Utilization of leucine by working rat heart. Am J Physiol 1980;239:E430-6.

163. Mudge GH, Jr., Mills RM, Jr., Taegtmeyer H, et al. Alterations of myocardial amino acid metabolism in chronic ischemic heart disease. J Clin Invest 1976;58:1185-92.

164. Camici P, Marraccini P, Lorenzoni R, et al. Metabolic markers of stress-induced myocardial ischemia. Circulation 1991;83:III8-13.

165.Liu Z, Vuohelainen V, Tarkka M, et al. Glutamate release predicts ongoing myocardial ischemia of rat hearts. Scand J Clin Lab Invest 2010;70:217-24.

166. Minamisawa M, Motoki H, Izawa A, et al. Comparison 
of Inflammatory Biomarkers in Outpatients With Prior Myocardial Infarction. Int Heart J 2016;57:11-7.

167. Bhattacharya S, Granger CB, Craig D, et al. Validation of the association between a branched chain amino acid metabolite profile and extremes of coronary artery disease in patients referred for cardiac catheterization. Atherosclerosis 2014;232:191-6.

168. Shah SH, Sun JL, Stevens RD, et al. Baseline metabolomic profiles predict cardiovascular events in patients at risk for coronary artery disease. Am Heart J 2012;163:844-50.e1.

169. Drake KJ, Sidorov VY, McGuinness OP, et al. Amino acids as metabolic substrates during cardiac ischemia. Exp Biol Med (Maywood) 2012;237:1369-78.

170. Frey N, Luedde M, Katus HA. Mechanisms of disease: hypertrophic cardiomyopathy. Nat Rev Cardiol 2011;9:91-100.

171.Hershberger RE, Hedges DJ, Morales A. Dilated cardiomyopathy: the complexity of a diverse genetic architecture. Nat Rev Cardiol 2013;10:531-47.

172.Kumar A, Rani B, Sharma R, et al. ACE2, CALM3 and TNNI3K polymorphisms as potential disease modifiers in hypertrophic and dilated cardiomyopathies. Mol Cell Biochem 2018;438:167-74.

173. Fischer-Rasokat U, Assmus B, Seeger FH, et al. A pilot trial to assess potential effects of selective intracoronary bone marrow-derived progenitor cell infusion in patients with nonischemic dilated cardiomyopathy: final 1-year results of the transplantation of progenitor cells and functional regeneration enhancement pilot trial in patients with nonischemic dilated cardiomyopathy. Circ Heart Fail 2009;2:417-23.

174. Staudt A, Schäper F, Stangl V, et al. Immunohistological changes in dilated cardiomyopathy induced by immunoadsorption therapy and subsequent immunoglobulin substitution. Circulation 2001;103:2681-6.

175.Pound KM, Sorokina N, Ballal K, et al. Substrateenzyme competition attenuates upregulated anaplerotic flux through malic enzyme in hypertrophied rat heart and restores triacylglyceride content: attenuating upregulated anaplerosis in hypertrophy. Circ Res 2009;104:805-12.

176.el Alaoui-Talibi Z, Landormy S, Loireau A, et al. Fatty acid oxidation and mechanical performance of volumeoverloaded rat hearts. Am J Physiol 1992;262:H1068-74.

177. Burelle Y, Wambolt RB, Grist M, et al. Regular exercise is associated with a protective metabolic phenotype in the rat heart. Am J Physiol Heart Circ Physiol 2004;287:H1055-63.
178.Lai EJ, Rakowski H. Physiologic or pathologic hypertrophy: how can we know? Expert Rev Cardiovasc Ther 2014;12:919-22.

179. Lai L, Leone TC, Keller MP, et al. Energy metabolic reprogramming in the hypertrophied and early stage failing heart: a multisystems approach. Circ Heart Fail 2014;7:1022-31.

180. Schisler JC, Grevengoed TJ, Pascual F, et al. Cardiac energy dependence on glucose increases metabolites related to glutathione and activates metabolic genes controlled by mechanistic target of rapamycin. J Am Heart Assoc 2015;4:e001136.

181. Kurdi M, Booz GW. Three 4-letter words of hypertensionrelated cardiac hypertrophy: TRPC, mTOR, and HDAC. J Mol Cell Cardiol 2011;50:964-71.

182. Klawitter J, Klawitter J, Agardi E, et al. Association of DJ-1/PTEN/AKT- and ASK1/p38-mediated cell signalling with ischaemic cardiomyopathy. Cardiovasc Res 2013;97:66-76.

183.Huang L, Zhang L, Li T, et al. Human Plasma Metabolomics Implicates Modified 9-cis-Retinoic Acid in the Phenotype of Left Main Artery Lesions in Acute ST-Segment Elevated Myocardial Infarction. Sci Rep 2018;8:12958.

184. DeFilippis AP, Trainor PJ, Hill BG, et al. Identification of a plasma metabolomic signature of thrombotic myocardial infarction that is distinct from non-thrombotic myocardial infarction and stable coronary artery disease. PLoS One 2017;12:e0175591.

185.Desmoulin F, Galinier M, Trouillet C, et al. Metabonomics analysis of plasma reveals the lactate to cholesterol ratio as an independent prognostic factor of short-term mortality in acute heart failure. PLoS One 2013;8:e60737.

186. Floegel A, Kuhn T, Sookthai D, et al. Serum metabolites and risk of myocardial infarction and ischemic stroke: a targeted metabolomic approach in two German prospective cohorts. Eur J Epidemiol 2018;33:55-66.

187.Ibanez B, James S, Agewall S, et al. 2017 ESC Guidelines for the management of acute myocardial infarction in patients presenting with ST-segment elevation: The Task Force for the management of acute myocardial infarction in patients presenting with ST-segment elevation of the European Society of Cardiology (ESC). Eur Heart J 2018;39:119-77.

188. Roffi M, Patrono C, Collet JP, et al. 2015 ESC Guidelines for the management of acute coronary syndromes in patients presenting without persistent ST-segment elevation: Task Force for the Management of Acute 
Coronary Syndromes in Patients Presenting without

Persistent ST-Segment Elevation of the European Society of Cardiology (ESC). Eur Heart J 2016;37:267-315.

189. Ponikowski P, Voors AA, Anker SD, et al. 2016 ESC

Guidelines for the diagnosis and treatment of acute and chronic heart failure: The Task Force for the diagnosis and treatment of acute and chronic heart failure of the European Society of Cardiology (ESC). Developed with the special contribution of the Heart Failure Association (HFA) of the ESC. Eur J Heart Fail 2016;18:891-975.

190. Petras M, Kalenska D, Samos M, et al. NMR plasma metabolomics study of patients overcoming acute myocardial infarction: in the first $12 \mathrm{~h}$ after onset of chest pain with statistical discrimination towards metabolomic

Cite this article as: Müller J, Bertsch T, Volke J, Schmid A, Klingbeil R, Metodiev Y, Karaca B, Kim SH, Lindner S, Schupp T, Kittel M, Poschet G, Akin I, Behnes M. Narrative review of metabolomics in cardiovascular disease. J Thorac Dis 2021;13(4):2532-2550. doi: 10.21037/jtd-21-22 biomarkers. Physiol Res 2020;69:823-34.

191.Zhang L, Wei TT, Li Y, et al. Functional Metabolomics Characterizes a Key Role for N-Acetylneuraminic Acid in Coronary Artery Diseases. Circulation 2018;137:1374-90.

192. Kohlhauer M, Dawkins S, Costa ASH, et al. Metabolomic Profiling in Acute ST-Segment-Elevation Myocardial Infarction Identifies Succinate as an Early Marker of Human Ischemia-Reperfusion Injury. J Am Heart Assoc. 2018;7:e007546.

193.Lema C, Andrés M, Aguadé-Bruix S, et al. (1)H NMR serum metabolomic profiling of patients at risk of cardiovascular diseases performing stress test. Sci Rep 2020;10:17838. 